\title{
Improvement of cylinder buckling knockdown factor through imperfection sensitivity
}

\begin{abstract}
This paper encompasses the work from numerical model by investigating the compression response of CFRP composite cylinder shells. The aim of this paper is to improve the reliability of NASA SP-8007 design guideline. The cylinder geometrical imperfections were tested through numerical modelling and validate with the experiment results. Good results comparison has been obtained through the work with small amount of errors. The cylinder shell load carrying capacity has been improved by average of 56\% through imperfection study. This work builds confidence in the future use of non-linear finite element for the design of composite cylinder subjected to axial compression load.
\end{abstract}

Keyword: Composite shell; Cylinder postbuckling; Finite element method; Knockdown factor 